\title{
The efficacy and safety of apatinib in metastatic alveolar soft part sarcoma: a case series of six patients in one institution
}

This article was published in the following Dove Press journal:

Cancer Management and Research

\section{Yitian Wang* \\ Li Min* \\ Yong Zhou \\ Fan Tang \\ Yi Luo \\ Wenli Zhang \\ Hong Duan \\ Chongqi Tu}

Department of Orthopedics, West China Hospital, Sichuan University, Chengdu 61004I, Sichuan, People's Republic of China

*These authors contributed equally to this work
Correspondence: Chongqi Tu

Department of Orthopedics, West China Hospital, Sichuan University, No. 37

Guoxuexiang, Chengdu 61004I, People's

Republic of China

$\mathrm{Tel}+8613980095430$

Fax +860 2885582944

Email tuchongqibone@hotmail.com
Background: Evidence suggests that advanced or metastatic alveolar soft part sarcoma (ASPS) with high metastatic potential is chemo-resistant. However, the benefits of tyrosine kinase inhibitors have been demonstrated for the treatment of ASPS.

Purpose: This study aimed to investigate the efficacy and safety of apatinib, aspecific VEGFR-2 inhibitor, in ASPS patients. This retrospective analysis involved six patients with metastatic ASPS not amenable to curative treatment.

Patients and methods: Apatinib was administered at a dose of 500mg per day. Tumor responses were assessed according to the Response Evaluation Criteria in Solid Tumors (RECIST 1.1) guidelines. Survival analysis was performed using the Kaplan-Meier test, and a safety profile was recorded.

Results: The mean age of patients was 26.5 (range, 17-32) years. The median progressionfree survival (PFS) was 18.53 months (95\% CI, 12.23-NE). However, median overall survival (OS) has not been reached. Twenty-four month PFS and OS rates were $50.0 \%$ and $100.0 \%$, respectively. One patient achieved a complete response, and the remaining patients achieved partial responses, with an objective response rate of $100 \%$. Median follow-up was 20.6 (range, 12.43-34.13) months. The most common adverse events included gastrointestinal discomfort (4/6[66.7\%]), hair hypopigmentation (4/6[66.7\%]) and hand-foot skin reaction $(3 / 6[50.0 \%])$.

Conclusion: Apatinib shows beneficial activity in metastatic ASPS patients, and further studies are warranted with more cases and longer follow-up periods to fully characterize clinical efficacy and safety of apatinib in ASPS.

Keywords: alveolar soft part sarcoma, apatinib, efficacy, safety, vascular endothelial growth factor

\section{Introduction}

Alveolar soft part sarcoma (ASPS) is a rare, mostly chemo-resistant soft tissue sarcoma (STS) subtype characterized by the unbalanced translocation $\mathrm{t}(\mathrm{X} ; 17)$ (p11.2; q25.3), which results in the ASPACR1-TFE3 fusion gene. ASPS accounts for only $0.5-1 \%$ of all STS. ${ }^{1,2}$ A paradoxical high metastatic rate, ${ }^{3,4}$ is characterized by metastasis to lungs, lymph nodes and bone. ${ }^{1,5,6}$ ASPS usually show an indolent course and occurs in the lower extremities, especially in the lower limbs. Some patients already show distant metastasis and invasion at initial visiting. ${ }^{1,7}$ These patients have a 5 -year survival rate of only $20 \%$, compared with $71 \%$ in patients 
with localized disease. ${ }^{8}$ Metastasis, together with large tumor size, older age, and a truncal primary site, are independent prognostic factors for ASPS. ${ }^{7}$

Complete excision of ASPS is the most common curative treatment, while radiotherapy may be recommended in patients without an $\mathrm{R}_{0}$ resection. ${ }^{1,9}$ The National Comprehensive Cancer Network (NCCN) suggests chemotherapy for advanced, inoperable and/or metastatic STS, but advanced or metastatic ASPS is generally not sensitive to conventional cytotoxic chemotherapy. ${ }^{1,5,8}$ The key role of pathological angiogenesis in STS progression, invasion and metastasis, ${ }^{10}$ and upregulation of angiogenic and metastatic targets, such as vascular endothelial growth factor (VEGF) and c-Met, were revealed in ASPS by transcriptomic analysis. ${ }^{5}$ In addition, ASPS is highly vascular, so the use of angiogenesis inhibitors may be effective for the treatment of metastatic ASPS. A number angiogenesis targeting agents have been used therapeutically for ASPS, including pazopanib, ${ }^{11}$ crizotinib, ${ }^{12}$ sorafenib $^{13}$ and anlotinib. ${ }^{14}$

Apatinib is a novel tyrosine kinase receptor inhibitor that selectively competes for the vascular endothelial growth factor receptor 2 (VEGFR-2) ATP binding site, blocking downstream signaling and inhibiting tumor angiogenesis. ${ }^{15}$ Apatinib improves progression-free survival (PFS) and overall survival (OS), in patients with advanced gastric cancer. ${ }^{16}$ It is considered to be useful for systemic treatment in patients with metastatic STS, including synovial sarcoma, undifferentiated pleomorphic sarcoma and malignant peripheral nerve sheath tumor. ${ }^{17,18}$

No prior case series has reported the efficacy and safety of apatinib in metastatic ASPS. Thus, this study aimed to investigate the efficacy of apatinib, a specific VEGFR-2 inhibitor, in patients with metastatic ASPS. We conducted a retrospective cohort study to evaluate the association of anti-angiogenesis related adverse events (AEs) with clinical outcomes in patients with metastatic ASPS, and report data from a total of 6 patients treated with apatinib. Our study describes the efficacy and safety of apatinib in patients with metastatic ASPS who were treated at the Department of Orthopaedics of the West China Hospital.

\section{Methods}

\section{Eligibility criteria}

The study was conducted retrospectively for patients treated from February 1, 2015, to July 18, 2018. The inclusion criteria included the following: 1) histologically proven ASPS; 2) initial treatment in the Department of Orthopedics of the West China Hospital; 3) patients with a diagnosis of metastatic ASPS deemed incurable by conventional surgery, radiotherapy or systemic therapy; 4) measurable lesions according to the Response Evaluation Criteria for Solid Tumors (RECIST); ${ }^{19}$ 5) no previous malignancy; 6) centrally reviewed pathology materials (representative slides).

\section{Treatment methods}

Apatinib was orally administered at dose of $500 \mathrm{mg}$ per day in the selected patients $(500 \mathrm{mg}$ once or $250 \mathrm{mg}$ twice daily). ${ }^{18}$ One treatment cycle was continuous for 28 days until progression or toxicity. Dose-limiting toxicity (DLT) was defined as possible or definite drug-related grade 3 to grade 4 toxic response. This study was performed according to the principles of the Declaration of Helsinki and the Institutional Review Board of Sichuan University West China Hospital. Written informed consent was obtained from all patients prior to treatment. The study protocol followed all appropriate guidelines according to the Declaration of Helsinki.

\section{Evaluation of efficacy and safety}

In our retrospective study, response to treatment was assessed according to RECIST (version 1.1) guidelines. We were mainly concerned with documenting disease control rate (DCR), defined as the percentage of patients achieving a complete response (CR), partial response (PR) and stable disease (SD); objective response rate (ORR) defined as the percentage of patients showing CR and PR; PFS, and OS. Treatment efficacy was evaluated by computed tomography (CT) for lung metastasis and magnetic resonance imaging (MRI) for the primary tumor. Additionally, adverse events (AEs) encountered were recorded on the basis of frequency and severity of events assessed according to the Common Terminology Criteria for Adverse Events.

\section{Statistical analysis}

Kaplan-Meier survival curves were used for PFS and OS estimation. Data analyses were performed using SPSS 20.0 software (IBM Corporation, Armonk, NY, USA). PFS was defined as the time from the date of diagnosis to the date of progression or last follow up. OS was defined as the time from the date of diagnosis to death or last follow up. Significance $(P<0.05$, two-tailed) was assessed by log-rank tests for PFS and OS. 
Table I Patient characteristics

\begin{tabular}{|c|c|}
\hline Characteristics & $\begin{array}{l}\text { Number of patients (percen- } \\
\text { tage \& range) }\end{array}$ \\
\hline \multicolumn{2}{|l|}{ Sex } \\
\hline Male & $5(83.3)$ \\
\hline Female & I (16.7) \\
\hline \multicolumn{2}{|l|}{ Age (years) } \\
\hline Median & $26.5(17-32)$ \\
\hline $10-17$ & I (16.7) \\
\hline$>17$ & $5(83.3)$ \\
\hline \multicolumn{2}{|l|}{ Metastatic site } \\
\hline Lung only & $6(100)$ \\
\hline \multicolumn{2}{|l|}{$\begin{array}{l}\text { Number of previous } \\
\text { treatment lines }\end{array}$} \\
\hline I & $5(83.3)$ \\
\hline 2 & I (16.7) \\
\hline \multicolumn{2}{|l|}{ Primary tumor site } \\
\hline Extremities & $4(83.3)$ \\
\hline Trunk & $2(16.7)$ \\
\hline \multicolumn{2}{|l|}{ Primary tumor size } \\
\hline$>5 \mathrm{~cm}$ & $5(83.3)$ \\
\hline$<5 \mathrm{~cm}$ & I (16.7) \\
\hline
\end{tabular}

\section{Results}

\section{Patient characteristics}

From February 1, 2015, to July 18, 2018, six consecutive patients were enrolled. All pathology materials were confirmed at West China Hospital. Patient clinical characteristics are shown in Tables 1 and 3. Median age was 26.5 (range, 17-32) years, and median followup time was 20.6 (range, 12.43-34.13) months. Before treatment with apatinib, one patient (16.7\%) had lung metastasis occurred one month after surgery, but disease progressed after one circle chemotherapy (gemcitabine $1000 \mathrm{mg} / \mathrm{m}^{2} \mathrm{~d}_{1,8}$ and docetaxel $75 \mathrm{mg} / \mathrm{m}^{2} \mathrm{~d}_{8}$ ). So apatinib was administered as the second-line therapy for this patient. The other five (83.3\%) patients had lung metastasis, deemed incurable by local or systemic therapy, at initial presentation. Thus apatinib was administered as first-line therapy in these patients. All the six patients were evaluated by physicians at our clinic on a monthly basis and chest CT and MRI of tumor lesions at the primary site were routinely performed.

\section{Efficacy}

By the last scheduled visit, all the patients were alive. The best response to apatinib by RECIST was: $1 \mathrm{CR}, 5 \mathrm{PR}$ (Figure 1). The ORR and DCR were similarly $100.00(95 \%$ CI, 54.07-100.00) (Tables 2 and 3). The median PFS was 18.53 months (95\% CI, 12.23-NE). However, median OS has not been reached. The 12- and 24-month OS rates were $100.0 \%$ each (Figure 2). And the 12-month and 24month PFS rates were 100.00 (95\%CI, 100.00-100.00) and $50.00 \%(95 \%$ CI 11.09-80.37), respectively (Figure 3).

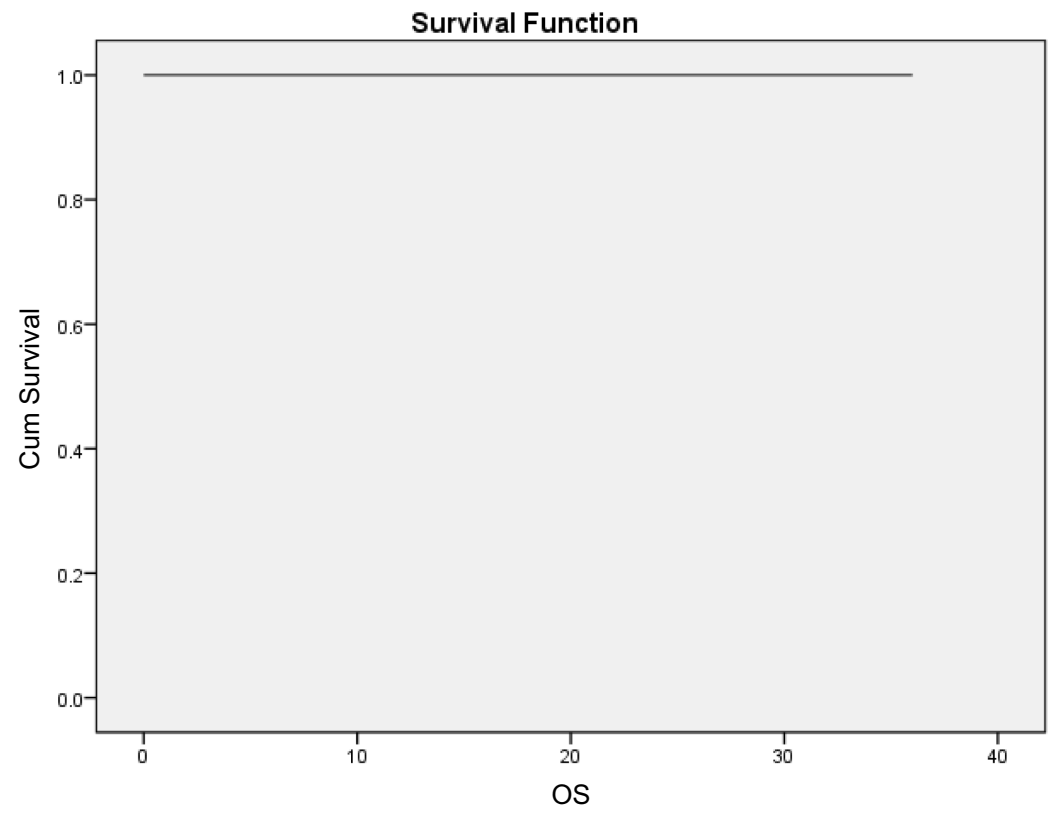

Figure I Kaplan-Meier estimates of progression free survival for all patients. 
Table 2 Patients' clinical evaluations

\begin{tabular}{|l|l|}
\hline $\begin{array}{l}\text { clinical } \\
\text { evaluation }\end{array}$ & $\begin{array}{l}\text { Number of patients (percentage \& } \\
\text { range) }\end{array}$ \\
\hline $\mathrm{N}$ (missing) & $6(0)$ \\
$C R$ & $1(16.67 \%)$ \\
$P R$ & $5(83.33 \%)$ \\
SD & $0(0.00 \%)$ \\
PD & $0(0.00 \%)$ \\
ORR $(95 \% \mathrm{Cl})$ & $100.00(54.07-100.00)$ \\
DCR $(95 \% \mathrm{Cl})$ & $100.00(54.07-100.00)$ \\
\hline
\end{tabular}

Abbreviations: $C R$, complete response; PR, partial response; SD, stable disease; $\mathrm{PD}$, progressive disease; $\mathrm{DCR}$, disease control rate (defined as the percentage of patients achieving a $C R+P R+S D$ ); $O R R$, objective response rate (including the percentage of $C R$ and $P R$ ); PFS, progression free survival; OS, overall survival.

\section{Safety and toxicity}

No adverse events were noted in any of the patients, and treatment continued uninterrupted. No new or unexpected AEs were noted (Table 4). Adverse events occurring in more than $10 \%$ of all the patients included the following: gastrointestinal discomfort $(4 / 6[66.7 \%])$, hair hypopigmentation $(4 / 6[66.7 \%])$ and hand-foot skin reaction (3/6[50.0\%]). All adverse reactions were mild (grade 1 or 2) and were easily controlled. No treatment-related death occurred, and no dose reductions were needed.

\section{Discussion}

Metastatic ASPS is resistant to conventional systemic therapies associated with microphthalmia transcription factor (MiT) ${ }^{1,8}$ The MiT gene family includes TFE3, TFEB, TFEC, and MiTF. ${ }^{20}$ ASPSCR1-TFE3 causes MET autophosphorylation and activation of downstream signaling such as PI3K/AKT and MAPK. ${ }^{21}$ These pathways drive pathological angiogenesis and tumor metastasis. Antiangiogenic strategies are emphasized for interrupting these pathways in patients with metastatic ASPS.

Several reports have revealed robust expression of angiogenesis in ASPS associated with vascular endothelial growth factor receptor (VEGFR)1, VEGFR2, VEGFR3, epidermal growth factor (EGF), MET, RET, plateletderived growth factor (PDGF)B, PDGFRB and innate immunity-related receptors such as toll-like receptors (TLR)2 and TLR9., 42

VEGF is one of the central drivers for angiogenesis, ${ }^{23}$ and VEGFR-2 is the key mediator of recognized VEGFinduced phenotypes. ${ }^{24}$ In vivo, the efficacy of antiangiogenic agents for the treatment of ASPS has been confirmed. ${ }^{25}$ Several clinical trials reported that antiangiogenic agents, such as pazopanib, ${ }^{11}$ crizotinib, ${ }^{12}$

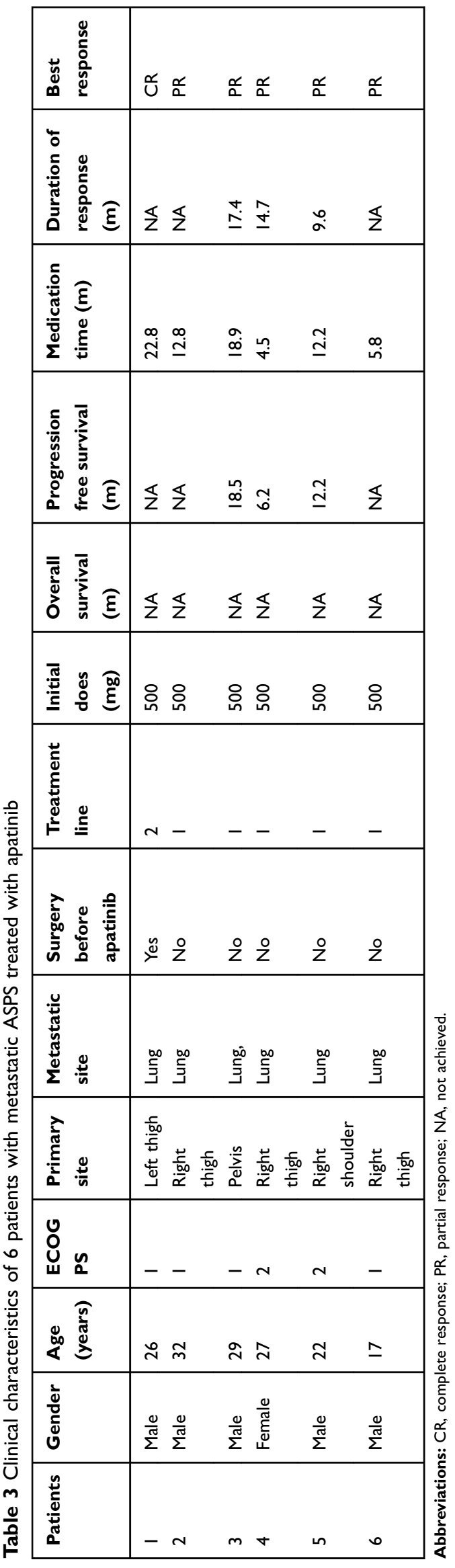




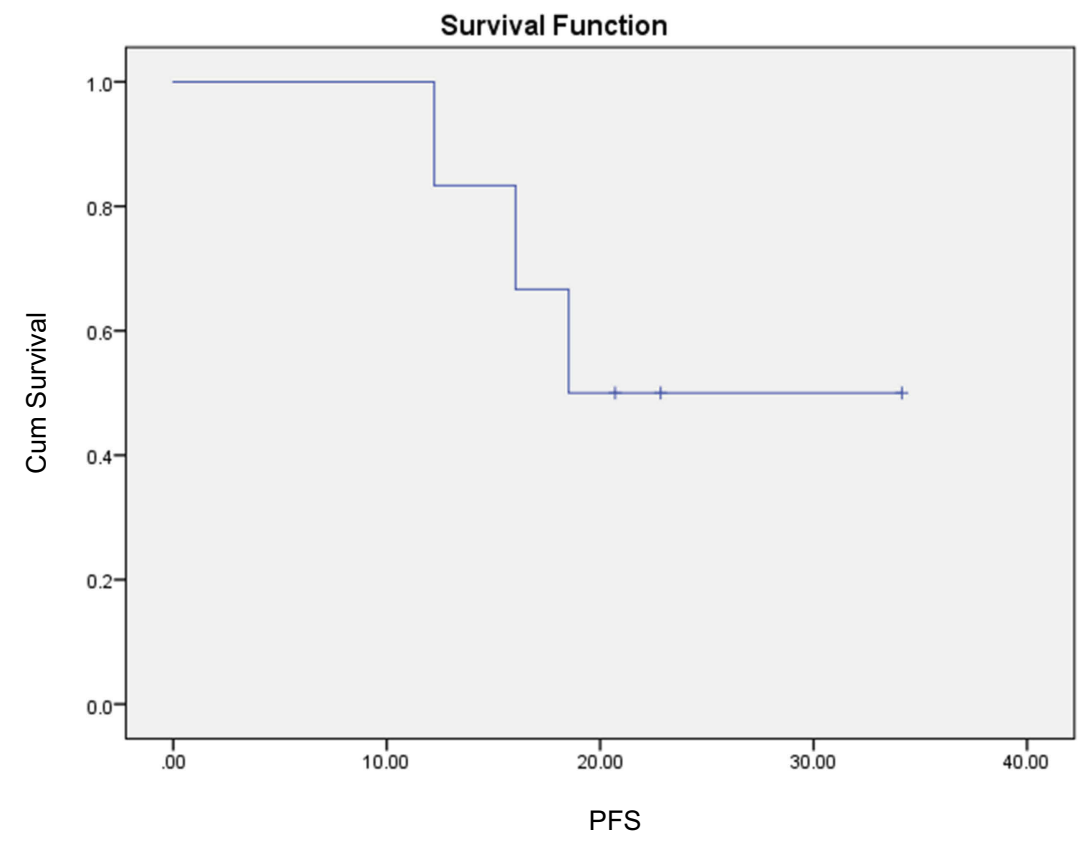

Figure 2 Kaplan-Meier estimates of progression free survival for all patients.

sorafenib, ${ }^{13}$ anlotinib, ${ }^{14}$ sunitinib ${ }^{26}$ and cediranib, ${ }^{13}$ can be effective in patients with ASPS results of these reports are summarized in Table 5. For advanced or metastatic ASPS, anti-angiogenic agents were often administered as firstor second-line treatment. Especially, a single patient may have received multiple targeted agents concurrently after disease progression. ${ }^{13}$ Rates of tumor growth and metastasis have been variable, and clinical benefits are difficult to assess. No severe adverse effects were reported, also no patients were withdrawn from treatment because of AEs. Overall, $11.0 \%$ of patients $(9 / 82)$ had PR as the best response. Maximum median PFS was 24.5 months.

Apatinib, a specific VEGFR-2 inhibitor, was licensed by the China Food and Drug Administration (CFDA) for the treatment of advanced/metastatic gastric cancer and adenocarcinomas of the gastroesophageal junction in 2014. Its anti-cancer effects have been reported for a broad range of malignancies, such as osteosarcoma, rhabdomyosarcoma, synovial sarcoma and alveolar soft part sarcoma. ${ }^{18,29}$

The main objective of this study was to evaluate the activity and safety of apatinib in metastatic ASPS. Only one study has evaluated the response of ASPS to apatinib. Xie et al reported results of apatinib use for advanced sarcoma. Three patients with advanced ASPS were administered apatinib as the second-line treatment after poor response to cytotoxic chemotherapy (gemcitabine $1000 \mathrm{mg} / \mathrm{m}^{2} \mathrm{~d}_{1,8}$ and docetaxel $75 \mathrm{mg} / \mathrm{m}^{2} \mathrm{~d}_{8}$ ). Two patients had PR with an average duration of response of 7.4 months. ${ }^{18}$ Apatinib was administered as the first-line treatment option for 5 patients and the second-line for one patient in our study, with the notable result of one CR and five PR. Median PFS was 18.53 months (95\% CI, 12.23-NE), a 24 -month OS rate was $100.0 \%$, and the $24-$ month PFS rate was $50.0 \%$. Since three of our patients were assessed as PD, the duration of response (DR) of patients could be partly evaluated (Table 3). Patient (No.6) with the best response (CP), showed poor response to conventional chemotherapy (Figure 4), and apatinib was used as a second-line treatment. He discontinued apatinib treatment after 5.8 months of treatment due to its economic burden. At the last follow-up, a recurrence of lung metastasis was found. Compared with the initial CT of the chest, response to treatment was PR. We conclude that the main difference between the two reports is chemotherapy. In ASPS, a larger tumor reflects a longer disease history and metastasis rate rather than tumor growth rate and biological aggressiveness. ${ }^{1}$ We speculate that the metabolism of tumor cells might differ ASPS and other STSs. Further, conventional chemotherapy agents primarily act on DNA or RNA in the cell cycle. Tumor cells are selected for insensitive chemotherapy, which contributes to the formation of chemotherapy-resistant ASPS. Thus, cytotoxic chemotherapy, including doxorubicin, gemcitabine and docetaxel, shows little efficacy. 


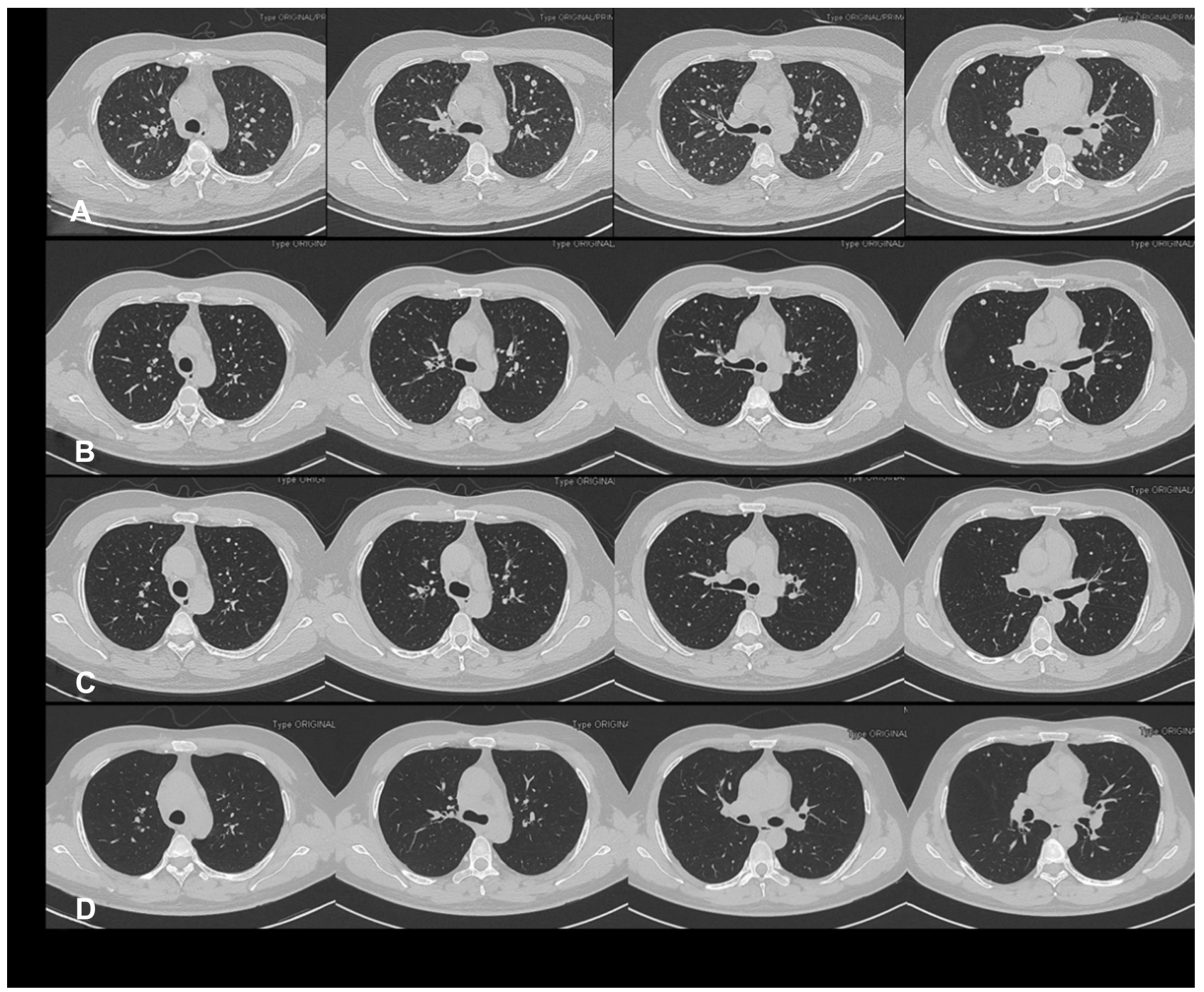

Figure 3 The patient with best response of PR. Chest CT of different periods are shown the nature of radiological response ([A] before apatinib treatment; [B] I month after targeted therapy; [C] 3 months after targeted therapy; [D] 7 months after targeted therapy).

Table 4 Adverse events

\begin{tabular}{|c|c|c|c|c|}
\hline \multirow[b]{2}{*}{$\mathrm{AE}$} & \multirow{2}{*}{$\begin{array}{l}\text { Total, } \\
\mathbf{N}\end{array}$} & \multicolumn{3}{|c|}{ Grade } \\
\hline & & I & 2 & $3-4$ \\
\hline $\begin{array}{l}\text { Gastrointestinal } \\
\text { discomfort }^{\mathrm{a}}\end{array}$ & 4 & 3 & I & 0 \\
\hline Hair hypopigmentation & 4 & 2 & 2 & 0 \\
\hline Hand-foot skin reaction & 3 & I & $\begin{array}{l}<\text { bold }>2<1 \\
\text { bold }>\end{array}$ & 0 \\
\hline Anorexia & 2 & 2 & 0 & 0 \\
\hline Oral ulcers & 2 & 2 & 0 & 0 \\
\hline Fatigue & 2 & I & I & 0 \\
\hline Wound-healing problems & I & I & 0 & 0 \\
\hline Proteinuria & I & I & 0 & 0 \\
\hline Hypothyroidism & I & 0 & 2 & 0 \\
\hline Hypertension & I & I & 0 & 0 \\
\hline
\end{tabular}

Notes: ${ }^{\mathrm{a}}$ Gastrointestinal discomfort means nausea/vomiting/diarrhea/ stomachache.
Previously, our institution used gemcitabine and docetaxel prior to targeted therapy for patients with metastatic ASPS, because of the central role of chemotherapy in systemic treatment according to the NCCN guidelines. However, in recent years, we changed our therapeutic strategy. First, since 2012, the NCCN guideline suggested sunitinib as a systemic agent for ASPS. Second, the efficacy of antiangiogenic drugs, especially sunitinib, was confirmed in patients with advanced or metastatic ASPS. ${ }^{14,22,26}$ Third, apatinib has been reported as the firstline treatment for off-label use in advanced or metastatic STS. ${ }^{18,30}$ Finally, CR occurred in a patient No.6 after two treatment cycles of apatinib. Subsequently, we administered apatinib as the first-line treatment in two patients with metastatic ASPS, and both of them showed PR. In general, for first-line treatment, Van et al suggested 
Table 5 anti-angiogenic agents for advanced or metastatic ASPS

\begin{tabular}{|c|c|c|c|c|c|c|}
\hline $\begin{array}{l}\text { Drug } \\
\text { (references) }\end{array}$ & $\begin{array}{l}\text { No. of } \\
\text { patients }\end{array}$ & $\begin{array}{l}\text { Age } \\
\text { (years) }\end{array}$ & $\begin{array}{l}\text { Tumor site } \\
\text { (primaryl } \\
\text { metastasis) }\end{array}$ & $\begin{array}{l}\text { Best } \\
\text { response }\end{array}$ & $\begin{array}{l}\text { Response duration } \\
\text { (month) }\end{array}$ & $\begin{array}{l}\text { Objective } \\
\text { response } \\
\text { rate }(\%)\end{array}$ \\
\hline Anlotinib $^{14}$ & 13 & $>18$ & NA & NA & $\begin{array}{l}\text { Median PFS } 21.0 \\
\text { Median OS NA } \\
24 \mathrm{~m} \text { OSR } 92 \%\end{array}$ & 46.0 \\
\hline Cediranib $^{13}$ & 2 & 12 and 17 & $\begin{array}{l}\text { Shoulder/lung, brain } \\
\text { Calf/lung }\end{array}$ & One SD & 10.5 & 0 \\
\hline Crizotinib $^{12}$ & 45 & $\begin{array}{l}\text { Median } 30 \\
(16-69)\end{array}$ & NA & Two PR & $\begin{array}{l}\text { Median PFS } 8.1 \\
\text { Median OS NA } \\
24 \mathrm{~m} \text { OSR } 81.2 \%\end{array}$ & 4.4 \\
\hline \multicolumn{7}{|l|}{ Pazopanib } \\
\hline Ricardo J. ${ }^{27}$ & 4 & $18-29$ & $\begin{array}{l}\text { Trunk and extremi- } \\
\text { ties/lung }\end{array}$ & One SD & $\begin{array}{l}\text { Median PFS } 24.5 \\
\text { Median OS NA }\end{array}$ & 0 \\
\hline Funakoshi et al ${ }^{28}$ & I & II & Thigh/lung & One PR & 8 & 100 \\
\hline Sorafenib ${ }^{13}$ & 2 & 12 and 17 & $\begin{array}{l}\text { Shoulder/lung, brain } \\
\text { Calf/lung }\end{array}$ & One PR & 22 & 50.0 \\
\hline Sunitinb ${ }^{26}$ & 15 & Median 32 & $\begin{array}{l}\text { Trunk and extremi- } \\
\text { ties/ } \\
\text { pelvis and lung }\end{array}$ & Six PR & $\begin{array}{l}\text { Median PFS } 19 \\
\text { Median OS NA }\end{array}$ & 40.0 \\
\hline
\end{tabular}

Abbreviations: $C R$, complete response; PR, partial response; SD, stable disease; PD, progressive disease; NA, not achieved; ORR, objective response rate (including the percentage of $C R$ and $P R)$; PFS, progression free survival; OS, overall survival; OSR, overall survival rate.

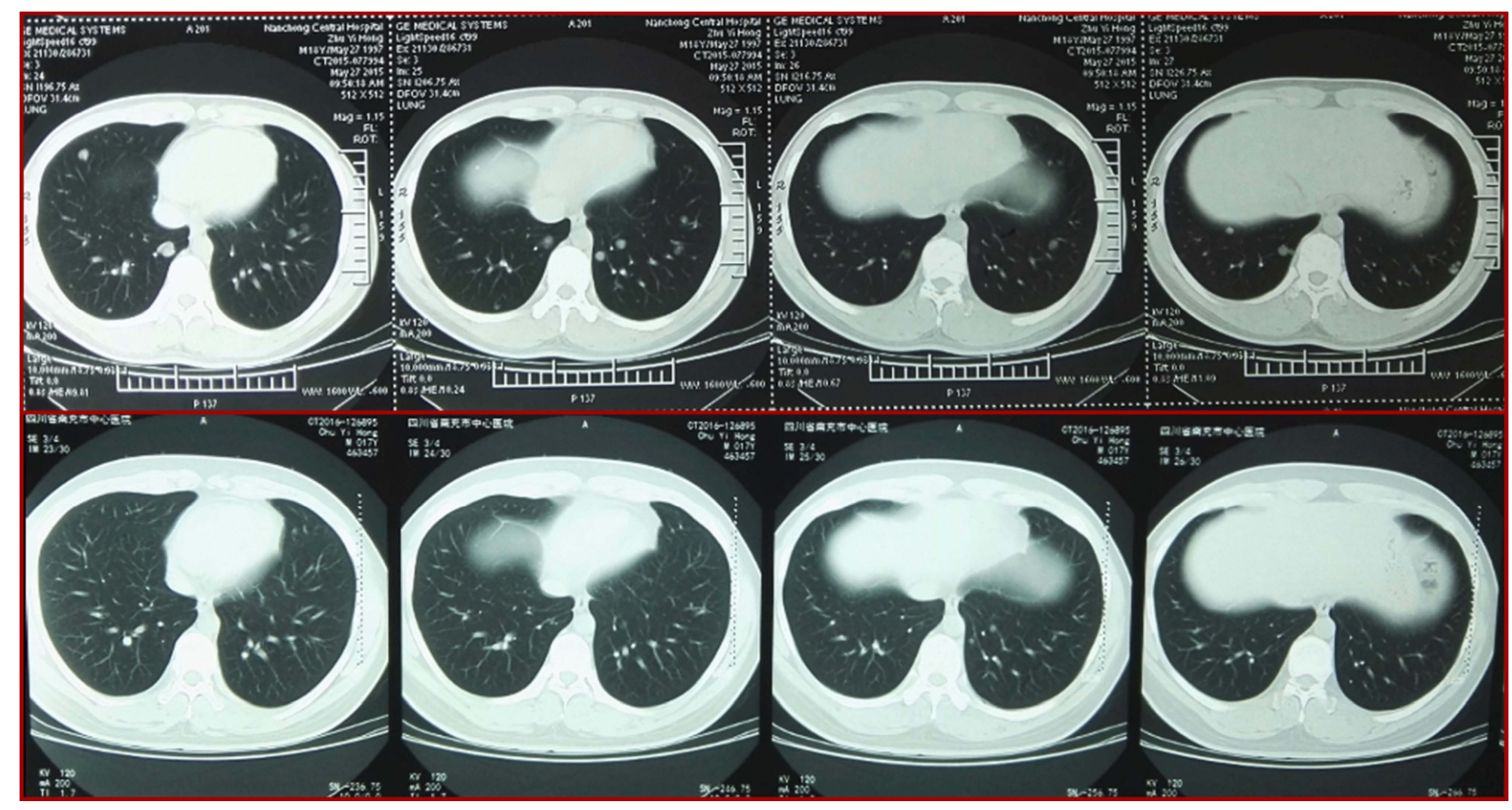

Figure 4 The patient with best response of CR. CT of chest are shown before and after treatment. 
a 6-month PFR of $>30-56 \%$ and for second-line therapy a 3-month PFR of $>40 \%$ as an indicator of promising activity. $^{31}$ Therefore, the results of our study, indicate that apatinib is an adequate choice for first-line treatment for patients with metastatic ASPS.

For the AEs, the most common toxicities previously reported are hand-foot skin reaction, fatigue and hypertension in the previous reports. ${ }^{29}$ Importantly, no patient had to discontinue apatinib because of AEs. The most common AEs in our study were gastrointestinal discomfort (4/6 [66.7\%]), hair hypopigmentation (4/6[66.7\%]) and handfoot skin reaction $(3 / 6[50.0 \%])$. Only one of our patients had hypertension and two complained of fatigue. No grade $3 / 4$ toxicities were observed. Interestingly, previous studies reported that patients with grade 3/4 toxicities had a longer PFS than those without the AE, especially for patients with hypertension and hand-foot skin reactions. ${ }^{32}$ Similar results were not found in our study, and we speculate the difference lies in the indolent behavior of ASPS.

Our study has some limitations. First, as a retrospective study, inclusion criteria utilized here were not as rigorous as those employed in formal prospective trials. We only enrolled six patients with the median follow-up time of 20.6 months. Further, it is still unclear when apatinib treatment should be stopped. Second, in spite of the encouraging results, our study is limited to clinical evaluation, lacking relevant molecular biology detection. For example, MET gene expression was not assessed. ${ }^{12}$ Third, although apatinib is known as a specific VEGFR-2 inhibitor, there remains a question whether apatinib also suppresses the activity of other factors such as EGF, PDGFR $\alpha / \beta$, Aurora-B, Ret, c-FMS, and c-Kit.

\section{Conclusion}

Our study provides the first evidence of the efficacy and safety of apatinib in patients with metastatic ASPS as a first-line medical option. Though the results are notable, drug resistance and AEs associated with apatinib remain controversial. Further multicenter randomized controlled trials with longer follow-up time will be required to completely characterize the efficacy and safety of apatinib in metastatic ASPS.

\section{Statement}

To preserve patient confidentiality and privacy, patient data have been de-identified before analysis. This retrospective study was performed based on the data from anonymized patients who received apatinib treatment between February 2015 and July 2018. Because of the nature of retrospective design and patient anonymization, the ethics of
Sichuan University West China Hospital approved the retrospective study and also determined that informed consent was not required.

\section{Acknowledgment}

This work was supported, in part, by the National Natural Science Foundation of China (81702664).

\section{Disclosure}

The authors report no conflicts of interest in this work. This research was presented at the ASCO held at Chicago, Illinois; June 1-5, 2018, as an online publication with interim findings. The abstract was published in DOI: 10.1200/JCO.2018.36.15_suppl.e23521, 36 no. 15_suppl in the Journal of Clinical Oncology.

\section{References}

1. Ogura K, Beppu Y, Chuman H, et al. Alveolar soft part sarcoma: a single-center 26-patient case series and review of the literature. Sarcoma. 2012;2012:907179. doi:10.1155/2012/907179

2. Williams A, Bartle G, Sumathi VP, et al. Detection of ASPL/TFE3 fusion transcripts and the TFE3 antigen in formalin-fixed, paraffin-embedded tissue in a series of 18 cases of alveolar soft part sarcoma: useful diagnostic tools in cases with unusual histological features. Virchows Arch. 2011;458:291-300. doi:10.1007/ s00428-010-1039-9

3. Pennacchioli E, Fiore M, Collini P, et al. Alveolar soft part sarcoma: clinical presentation, treatment, and outcome in a series of 33 patients at a single institution. Ann Surg Oncol. 2010;17:3229-3233. doi:10.1245/s10434-010-1186-x

4. Selvarajah S, Pyne S, Chen E, et al. High-resolution array CGH and gene expression profiling of alveolar soft part sarcoma. Clin Cancer Res. 2014;20:1521-1530. doi:10.1158/1078-0432.CCR-13-2090

5. Stockwin LH, Vistica DT, Kenney S, et al. Gene expression profiling of alveolar soft-part sarcoma (ASPS). BMC Cancer. 2009;9:22. doi:10.1186/1471-2407-9-22

6. Mitton B, Federman N. Alveolar soft part sarcomas: molecular pathogenesis and implications for novel targeted therapies. Sarcoma. 2012;2012:428789. doi:10.1155/2012/428789

7. Wang H, Jacobson A, Harmon DC, et al. Prognostic factors in alveolar soft part sarcoma: A SEER analysis. J Surg Oncol. 2016;113:581-586. doi:10.1002/jso.24183

8. Portera CA Jr., Ho V, Patel SR, et al. Alveolar soft part sarcoma: clinical course and patterns of metastasis in 70 patients treated at a single institution. Cancer. 2001;91:585-591.

9. Casanova M, Ferrari A, Bisogno G, et al. Alveolar soft part sarcoma in children and adolescents: A report from the soft-tissue sarcoma italian cooperative group. Ann Oncol. 2000;11:1445-1449.

10. Rouhi P, Lee SL, Cao Z, Hedlund EM, Jensen LD, Cao Y. Pathological angiogenesis facilitates tumor cell dissemination and metastasis. Cell Cycle. 2010;9:913-917. doi:10.4161/cc.9.5.10853

11. Stacchiotti S, Mir O, Le Cesne A, et al. Activity of pazopanib and trabectedin in advanced alveolar soft part sarcoma. Oncologist. 2018;23:62-70. doi:10.1634/theoncologist.2017-0161

12. Schoffski P, Wozniak A, Kasper B, et al. Activity and safety of crizotinib in patients with alveolar soft part sarcoma with rearrangement of TFE3: European Organization for Research and Treatment of Cancer (EORTC) phase II trial 90101 'CREATE'. Ann Oncol. 2018;29:758-765. doi:10.1093/annonc/mdx774 
13. Kuo DJ, Menell JS, Glade Bender JL. Treatment of metastatic, refractory alveolar soft part sarcoma: case reports and literature review of treatment options in the Era of targeted therapy. $J$ Pediatr Hematol Oncol. 2016;38:e169-72. doi:10.1097/MPH.0000000000 000571

14. Chi Y, Fang Z, Hong X, et al. Safety and efficacy of anlotinib, a multikinase angiogenesis inhibitor, in patients with refractory metastatic soft-tissue sarcoma. Clin Cancer Res. 2018. doi:10.1158/10780432.CCR-17-3766

15. Li J, Zhao X, Chen L, et al. Safety and pharmacokinetics of novel selective vascular endothelial growth factor receptor-2 inhibitor YN968D1 in patients with advanced malignancies. BMC Cancer. 2010;10:529. doi:10.1186/1471-2407-10-663

16. Li J, Qin S, Xu J, et al. Randomized, double-blind, placebo-controlled phase iii trial of apatinib in patients with chemotherapy-refractory advanced or metastatic adenocarcinoma of the stomach or gastroesophageal junction. $J$ Clin Oncol. 2016;34:1448-1454. doi:10.1200/JCO.2015.63.5995

17. Ji G, Hong L, Yang P. Successful treatment of advanced malignant fibrous histiocytoma of the right forearm with apatinib: a case report. Onco Targets Ther. 2016;9:643-647. doi:10.2147/ OTT.S96133

18. Xie L, Guo W, Wang Y, Yan T, Ji T, Xu J. Apatinib for advanced sarcoma: results from multiple institutions' off-label use in China. BMC Cancer. 2018;18:396. doi:10.1186/s12885-018-4242-8

19. Taylor PT, Haverstick D. Re: new guidelines to evaluate the response to treatment in solid tumors (ovarian cancer). J Nat Cancer Inst. 2005;97:151; author reply 2. doi:10.1093/jnci/dji080

20. Davis IJ, Fisher DE. MiT transcription factor associated malignancies in man. Cell Cycle. 2007;6:1724-1729. doi:10.4161/ cc.6.14.4484

21. Stacchiotti S, Tamborini E, Marrari A, et al. Response to sunitinib malate in advanced alveolar soft part sarcoma. Clin Cancer Res. 2009;15:1096-1104. doi:10.1158/1078-0432.CCR-08-2050

22. Stacchiotti S, Negri T, Zaffaroni N, et al. Sunitinib in advanced alveolar soft part sarcoma: evidence of a direct antitumor effect. Ann oncol. 2011;22:1682-1690. doi:10.1093/annonc/mdq644
23. English WR, Lunt SJ, Fisher M, et al. Differential expression of VEGFA isoforms regulates metastasis and response to anti-VEGFA therapy in sarcoma. Cancer Res. 2017;77:2633-2646. doi:10.1158/ 0008-5472.CAN-16-0255

24. Autiero M, Waltenberger J, Communi D, et al. Role of PlGF in the intra- and intermolecular cross talk between the VEGF receptors Flt1 and Flk1. Nat Med. 2003;9:936. doi:10.1038/ nm884

25. Vistica DT, Hollingshead M, Borgel SD, et al. Therapeutic vulnerability of an in vivo model of alveolar soft part sarcoma (ASPS) to antiangiogenic therapy. J Pediatr Hematol Oncol. 2009;31:561-570. doi:10.1097/MPH.0b013e3181a6e043

26. Jagodzinska-Mucha P, Switaj T, Kozak K, et al. Long-term results of therapy with sunitinib in metastatic alveolar soft part sarcoma. Tumori. 2017;103:231-235. doi:10.5301/tj.5000617

27. Flores RJ, Harrison DJ, Federman NC, et al. Alveolar soft part sarcoma in children and young adults: A report of 69 cases. Pediatr Blood Cancer. 2018;65:e26953. doi:10.1002/pbc.26953

28. Funakoshi Y, Okada M, Kawata S, Ito N, Abe K, Moriuchi H. The significant effects of pazopanib on multiple pulmonary metastatic lesions of alveolar soft part sarcoma: a case report. J Pediatr Hematol Oncol. 2017;39:238-239. doi:10.1097/ MPH.0000000000000736

29. Zhu B, Li J, Xie Q, Diao L, Gai L, Yang W. Efficacy and safety of apatinib monotherapy in advanced bone and soft tissue sarcoma: an observational study. Cancer Biol Ther. 2018;19:198-204. doi:10.1080/15384047.2017.1416275

30. Zhu B, Li J, Xie Q, Diao L, Gai L, Yang W. Efficacy and safety of apatinib monotherapy in advanced bone and soft tissue sarcoma: an observational study. Cancer Biol Ther. 2018;19(3):198-204.

31. Van Glabbeke M, Verweij J, Judson I, Nielsen OS, Tissue ES, Bone Sarcoma G. Progression-free rate as the principal end-point for phase II trials in soft-tissue sarcomas. Eur $J$ Cancer. 2002;38:543-549.

32. Li J, Wang L. Efficacy and safety of apatinib treatment for advanced esophageal squamous cell carcinoma. Onco Targets Ther. 2017;10:3965-3969. doi:10.2147/OTT.S132756

\section{Publish your work in this journal}

Cancer Management and Research is an international, peer-reviewed open access journal focusing on cancer research and the optimal use of preventative and integrated treatment interventions to achieve improved outcomes, enhanced survival and quality of life for the cancer patient.
The manuscript management system is completely online and includes a very quick and fair peer-review system, which is all easy to use. Visit http://www.dovepress.com/testimonials.php to read real quotes from published authors. 